\title{
Rain attenuation distribution for satellite microwave links application in Tanzania
}

\author{
Promota Haule, Hashim Iddi, Mussa Kissaka \\ Department of Electronics and Telecommunication Engineering, University of Dar es Salaam (UDSM)
}

\begin{tabular}{l} 
Article Info \\
\hline Article history: \\
Received Jan 10, 2019 \\
Revised May 1, 2019 \\
Accepted Jul 1, 2019 \\
\hline
\end{tabular}

\section{Keywords:}

$\mathrm{Ku}$ And Ka Bands

Rain Attenuation

Rain Rate

Satellite Links

\begin{abstract}
Rain rate and Rain Attenuation predictions are important in radio system operating at $\mathrm{Ku}$ and $\mathrm{Ka}$ bands as they affect telecommunication systems performance. To adequately estimate rain-induced attenuation and fading, the International Telecommunication Union (ITU) recommends for the use of rainfall data collected by using 1-minute integration time. Tanzania lacks rainfall data with 1-minute integration time, which is available either through measurements or conversion from rainfall data with longer integration time. In this paper the rain attenuation is predicted for seven locations in the coastal area of Tanzania. The 1 - minute rainfall rate is determined by Chebil's model by using long-term measurements from Tanzania Metrological Agency (TMA) collected for a period of forty years. The results which were obtained were used to estimate rain attenuations. By using the International Telecommunication Union-Recommendation (ITU-R) model, rain attenuation is predicted at horizontal polarization at $\mathrm{Ku}$ and $\mathrm{Ka}$ band. It is observed that, the attenuation is of ultimate effect in Unguja and least in Kibaha. The results obtained from this study can be used to design earthsatellite microwave links in the coastal area of Tanzania
\end{abstract}

Copyright $\odot 2020$ Institute of Advanced Engineering and Science. All rights reserved.

\section{Corresponding Author:}

Promota Haule,

Department of Electronics and Telecommunications Engineering,

University of Dar es Salaam, Tanzania.

Email: promotalinga@gmail.com

\section{INTRODUCTION}

Initially satellite communication in Tanzania was allocated for conventional frequency bands L ( $1 / 2$ $\mathrm{GHz}), \mathrm{S}(2 / 4 \mathrm{GHz})$ and $\mathrm{C}(4 / 6 \mathrm{GHz})$. An increasing growth of satellite communications due to high demand of data rate services and applications has led to spectral congestion of these conventional bands necessitating the use of the higher bands such as $\mathrm{Ku}$ and Ka bands. These higher bands are now widely used for a variety of potential applications and services such as direct broadcast satellite television, tele-medicine, navigation, remote sensing, distributed sensor networks and wireless access to Internet.

Satellite communication in Tanzania uses Very Small Aperture Terminal (VSAT) technology at Ku band. Experience shows that, as demands for broadband services increase, the lower frequency bands get congested leading to the need of migration to higher frequency bands. For Tanzania, this would translate into migration to $\mathrm{Ka}$ band. However, at frequencies above $10 \mathrm{GHz}$ in temperate and $7 \mathrm{GHz}$ in equatorial and tropical area where intense rainfall occurs, the most significant impairment to radio signal transmission is due to rainfall [1-5]. Rain causes radio waves to suffer from scattering, absorption and depolarization because at these frequencies, the diameter of raindrops is of the same order of magnitude as the radio signal wavelength. The rain induced scattering, absorption and depolarization of the radio signals cause severe signal attenuation (fading). The rain induced signal fading is more serious than multipath fading [6]. It is therefore very important to make an accurate prediction of rain induced attenuation on propagation paths when planning satellite communication system links. 
Rain induced signal fading is an important parameter in radio system operation as it affects system reliability and availability. A detailed knowledge of rainfall characteristics is, therefore, necessary for optimal planning and design to achieve the required Quality of Service (QoS) for earth-satellite communication systems. Different location over the world has its own rainfall rate. The amount of rain attenuation depends on the rainfall rate. The rain attenuation in different frequency bands is also different. Thus, to adequately estimate rain-induced attenuation and fading for particular location using local rainfall data is very significant. However, very few sites in the world [7, 8] and even fewer in Africa, [9-13] have conducted the study on the effect of rain attenuation on radio wave propagation in microwave and millimeter bands.

In Tanzania, there are neither studies on rain attenuation effects at higher frequency bands (above $10 \mathrm{GHz}$ ) nor rainfall measurements with short integration of rain attenuation prediction. The collected rainfall data are oriented towards agricultural, hydrological purposes and weather forecast management. Since these measurements require high resolution, the rain rates collected were in the intervals of daily, monthly and yearly. As a result, most rain gauges, currently used in Tanzania, do not have adequate resolution to measure short integration rates. For prediction of rain attenuation, there is a need, therefore, to convert the long integration time rainfall data available into the 1minute integration time as recommended by ITU-R [8, 14-17].

In this paper, 1-minute integration time rain rate cumulative distribution is determined by Chebil's model using the annual long-term measurements from Tanzania Metrological Agency (TMA) collected for a period of forty years. The rain attenuation is predicted by using the ITU-R model for seven locations: Dar es Salaam, Kibaha, Kilwa, Mtwara, Tanga, Pemba and Unguja which are located in the coastal area of Tanzania and experience high rainfall intensity. Results obtained from this study can be useful in the preliminary design of earth-satellite microwave links in the coastal area of Tanzania.

\section{RAIN RATE DISTRIBUTION IN TANZANIA}

The rainfalls in Tanzania are influenced by monsoon winds which blow at different times of the year eastwards from either south or north and referred to as Intertropical convergence zone (ICTZ). ICTZ influences the long rains when it moves northwards through East Africa in the months of March to May (MAM) and short rains when it blows southwards through East Africa in the months of October to December (OND) [5]. Tanzania's rainfall fell under two regimes namely unimodal and bimodal patterns. A large part of the country experiences unimodal rainfall with single rain season between November and April. This includes southern, central and western part of the country. The bimodal rainfall regime occurs in the eastern and northern coast, island of Zanzibar and Lake Victoria basin, with short rains from OctoberDecember and long rains between March and May. The average duration of the dry season is 5 to 6 months. The mean annual rainfall varies from 500 millimeters to 2,600 millimeters with the highest rate in Bukoba due to its location along the lake shores while the minimum is experienced in relatively dry northern areas of Kilimanjaro. To predict rain attenuation for Tanzania, daily rainfall data were analyzed and computed to get an average annual accumulation $(\mathrm{mm} / \mathrm{hr})$.

The satellite link failure is caused by fading of the signal which in turn depends on instantaneous rain rate variation occurring over the year. For this reason, the estimation of the rain attenuation is done by using the cumulative distribution (CD) of the rain across the years. Several models can be applied with the average annual rainfall accumulation $(\mathrm{mm} / \mathrm{yr})$ in order to obtain the $\mathrm{CD}$. Example of such model includes: Moupfouma and Martin [18], Chebil [19], Rice- Holmberg [20], and the global International Telecommunion Union (ITU) standard models [21]. ITU has established rain climate zones that can be used to obtain expected median cumulative distribution of rain rate for the whole world. However, the most recent study reveals that these data when used for tropical and equatorial regions will either underestimate or overestimate the rain attenuation [22]. The ITU has classified the coast area of Tanzania at rainfall the rate of $60 \mathrm{~mm} / \mathrm{hr}$.

This study adopts Chebil model, which uses the long term mean annual rainfall $\mathrm{M}(\mathrm{mm})$ at the location of interest. The model is used to estimate the 1-minute integrated complementary cumulative distribution functions (CDF) of the rain rate by using the available data from Tanzania Meteorological Agency service recorded for a period of forty years. The model uses the power law relationship given in (1):

$$
R_{0.01}=\alpha M^{\beta}
$$

The model has been compared with the other five models and used to measure values of R0.01 and average annual precipitation in Malaysia, Indonesia, Singapore, Brazil and Vietnam, where it produced the best estimate of the measured data than the rest [23]. Where $\alpha$ and $\beta$ are the regression coefficients of 12.2903 and 0.2973 respectively obtained from the Map in [20]. R0.01 (mm/hr) is the rainfall rate exceeded 
for $0.01 \%$ of the time. Using Chebil model, the estimation of the point rain rate $\mathrm{R}(\mathrm{mm} / \mathrm{hr})$ exceeded for $0.01 \%$ of an average year for all seven locations of coastal area is presented in Table 1 .

Table 1, show that Unguja has the highest rain rate distribution at $0.01 \%$ of outage time with $112 \mathrm{~mm} / \mathrm{hr}$; Pemba has $109 \mathrm{~mm} / \mathrm{hr}$; Tanga has $103 \mathrm{~mm} / \mathrm{hr}$; Dar es Salaam has $99 \mathrm{~mm} / \mathrm{hr}$; Mtwara has $98 \mathrm{~mm} / \mathrm{hr}$; Kilwa has $95 \mathrm{~mm} / \mathrm{hr}$; and Kibaha has $94 \mathrm{~mm} / \mathrm{hr}$ which is the lowest rain rate. The results of rainfall rate show that the ITU map [21] underestimate the rainfall rate cumulative distribution in the coastal part of Tanzania by almost $50 \%$.

Table 1. R0.01 in Coastal Locations in Tanzania

\begin{tabular}{ccc}
\hline Station Name & $\mathbf{M}(\mathbf{m m} / \mathbf{y r})$ & $\mathbf{R}_{\mathbf{0 . 0 1}}(\mathbf{m m} / \mathbf{h r})$ \\
\hline Dar Es Salaam & 1096.25 & $\mathbf{9 9}$ \\
Kibaha & 933.3 & $\mathbf{9 4}$ \\
Kilwa & 956 & $\mathbf{9 5}$ \\
Mtwara & 1093.96 & $\mathbf{9 8}$ \\
Pemba & 1540 & $\mathbf{1 0 9}$ \\
Tanga & 1274 & $\mathbf{1 0 3}$ \\
Unguja & 1676.063 & $\mathbf{1 1 2}$ \\
ITU Map & & $\mathbf{6 0}$ \\
\hline
\end{tabular}

\section{RAIN ATTENUATION PREDICTION MODEL}

Several researchers have developed rain attenuation prediction models. ITU-R is the widely used model compared to other models designed to meet local predictions. The ITU-R is designed for wide range of frequencies, different rain climates and elevation angles. The model is used to estimate the long term average of slant path rain attenuation up to frequencies of $55 \mathrm{GHz}$. To predict rain attenuation at a given location, the following two parameters are required:

- Specific attenuation/attenuation coefficient: the rain attenuation per kilometre in a rainy medium.

- Effective slant path length

The specific attenuation $\gamma \mathrm{R}$ is calculated by using $\mathrm{R} 0.01(\mathrm{~mm} / \mathrm{hr})$ and frequency and polarization dependent coefficients $\mathrm{k}$ and $\alpha$ which are given in the recommendation ITU-R P.838 [24] as presented in (2). The parameter R0.01 is obtained from rainfall measurement by using 1-minute integration time. If the value cannot be obtained from local data sources, an estimate can be obtained from the rainfall map of ITU-R P.837.

$$
\gamma_{R}=k\left(R_{0.01}\right)^{\alpha}(\mathrm{dB} / \mathrm{km})
$$

The effective slant path LE is calculated by using elevation angle $\theta$, Latitude $\varnothing$, altitude hs (km) and rain height $h R$ which are obtained from recommendation by ITU-R P 839. After obtaining $\gamma \mathrm{R}$ and LE, the attenuation exceeded by $0.01 \%$ of an average year can be calculated by using (3).

$$
A_{0.01}=\gamma_{R} L_{E}(\mathrm{~dB})
$$

The rain attenuation exceeded for other percentage of time $\mathrm{p}$ in the year between the range $0.001 \%$ to $5 \%$ can be calculated using (4). Equation (2-4) provides an estimated long-term statistic for attenuation caused by the rain.

$$
A_{p}=A_{0.01}\left(\frac{p}{0.01}\right)^{-\left(0.655+0.033 \ln (p)-0.045 \ln \left(A_{0.01}\right)-\beta(1-p) \sin \theta\right)}
$$

\section{RAIN ATTENUATION PREDICTION}

The rain attenuation to earth-satellite radio link depends on a number of factors, including point rain rate, frequency, elevation angle, $0 \mathrm{oC}$ isotherm height, height of the earth station from the mean sea level, and so on. The data which was used to estimate the attenuation due to the rain for R0.01 in Tanzania was collected over the period of forty years, and Chebil model which uses long term annual rainfall (mm) was used. 
This paper has used the ITU-R model [25] to predict the attenuation in Ku and Ka bands. The model can estimate the attenuation caused by rain up to the frequency of $55 \mathrm{GHz}$. For the prediction of each location, among the seven stations, a program was written in Matlab software by using the following input parameters: The values of the parameters are presented in Table 2.

- The point rainfall rate for the location by $0.01 \%$ of an average year $(\mathrm{R} 0.01)$ in $\mathrm{mm} / \mathrm{hr}$

- Altitude/Height above mean sea level of the earth station $(\mathrm{km})$

- Elevation angle (degrees)

- Latitude of the earth station (degrees)

- Frequency (Ghz)

- Effective radius of the earth $(8500 \mathrm{~km})$

Table 2. Input Parameters for the Rain Attenuation Algorithms for $11.356 \mathrm{Ghz}$ and $21.749 \mathrm{GHz}$

\begin{tabular}{cccccc}
\hline Station Name & Lat $\left({ }^{\circ} \mathbf{S}\right)$ & Long $\left({ }^{\circ} \mathbf{E}\right)$ & Altitude 9(m) & Elevation angle & $\mathbf{R}_{\mathbf{0 . 0 1}}(\mathbf{m m} / \mathbf{h r})$ \\
\hline Dar es Salaam & $6^{\circ} 52^{\prime}$ & $39^{\circ} 12^{\prime}$ & 53 & 52 & $\mathbf{9 9}$ \\
Kibaha & $6^{\circ} 50^{\prime}$ & $38^{\circ} 58^{\prime}$ & 167 & 52 & $\mathbf{9 4}$ \\
Kilwa & $8^{\circ} 55^{\prime}$ & $39^{\circ} 30^{\prime}$ & 14 & 51 & $\mathbf{9 5}$ \\
Mtwara & $10^{\circ} 21^{\prime}$ & $40^{\circ} 11^{\prime}$ & 113 & 50 & $\mathbf{9 8}$ \\
Pemba & $5^{\circ} 25^{\prime}$ & $39^{\circ} 82^{\prime}$ & 46 & 52 & $\mathbf{1 0 9}$ \\
Tanga & $5^{\circ} 5^{\prime}$ & $39^{\circ} 4^{\prime}$ & 49 & 52 & $\mathbf{1 0 3}$ \\
Unguja & $6^{\circ} 13^{\prime}$ & $39^{\circ} 13^{\prime}$ & 18 & 52 & $\mathbf{1 1 2}$ \\
\hline
\end{tabular}

The cumulative distributions of rain attenuation for seven locations in the Coastal zone of Tanzania namely; Dar es Salaam, Kibaha, Kilwa, Mtwara, Pemba, Tanga and Unguja were obtained at Ku and Ka bands of frequencies $11.356 \mathrm{Ghz}$ and $21.749 \mathrm{Ghz}$ (these values were used for calculation and were referred to as centre frequencies of operation for downlinks respectively) on 7oE EUTELSAT 7B satellite with horizontal polarization. The satellite is among the few satellites operating at higher frequency bands (Ku and Ka) covering Tanzania.

\section{SIMULATION RESULT}

The simulation results are achieved by writing a programme into Matlab software version R2017a to obtain rain induced attenuation at $\mathrm{Ku}$ and $\mathrm{Ka}$ downlink frequency bands for the coastal line of Tanzania based on the local climatological. Figures 1 and 2 present the cumulative distribution of rain attenuation exceeded at different percentage of time ranging from $0.001 \%$ to $5 \%$ of an average year for $\mathrm{Ku}$ and $\mathrm{Ka}$ bands in seven locations of the coast area. The results show that there is a difference in both $\mathrm{Ku}$ and $\mathrm{Ka}$ bands predicted attenuation values over each of the location. Unguja has the highest average annual rainfall accumulation with rain attenuation as high as $\sim 53.22 \mathrm{~dB}$ for Ka band and $\sim 15.14 \mathrm{~dB}$ for Ku band, making the difference of about $38.08 \mathrm{~dB}$ between the two frequencies bands. On the other hand, Kibaha is the location with the lowest average annual rainfall accumulation in the coast part of the country. The rain attenuation is $\sim 47.27 \mathrm{~dB}$ for $\mathrm{Ka}$ band while it is $\sim 13.41 \mathrm{~dB}$ for $\mathrm{Ku}$ band, making the difference of $33.86 \mathrm{~dB}$ between the frequency bands. These results were taken at $0.01 \%$ of the time exceeded. When comparing the results of this study to the ITU-R rain rate specification of $60 \mathrm{~mm} / \mathrm{hr}$, for example, in Unguja, the rain attenuation at $\mathrm{Ku}$ and Ka bands for $0.01 \%$ were $10.3 \mathrm{~dB}$ and $36.85 \mathrm{~dB}$ respectively, resulting in a relative error of $32 \%$ and $30 \%$ respectively. The higher values of rain attenuation observed are due the fact that the coastal area in Tanzania experience high rainfall intensity as compared to the one specified by ITU-R. This study justifies the need for further studies for determining the rain attenuation in other parts of the Tanzania.

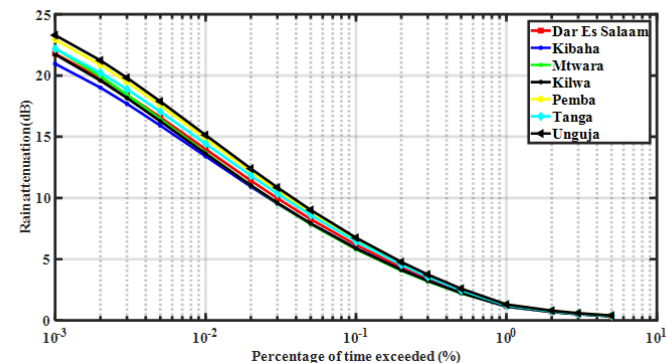

Figure 1. Rain attenuation distribution for Ku band

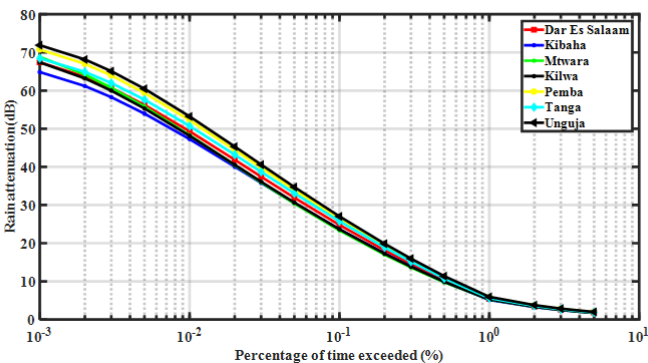

Figure 2. Rain attenuation distribution for Ka band Rain attenuation distribution for satellite microwave links application in Tanzania (Promota Haule) 


\section{CONCLUSION}

In this paper, the point rain rate $\mathrm{R}(\mathrm{mm} / \mathrm{hr})$ exceeded by $0.01 \%$ of an average is determined by the use of Chebil's model for seven geographical locations in the coastal part of Tanzania. The Chebil model converts local measurements of an average annual accumulation into 1-minute integration time rain rate distribution. By using the ITU model, the rain attenuation at different locations was predicted at horizontal polarization at $\mathrm{Ku}$ and $\mathrm{Ka}$ bands. It was found that the attenuation is highest in Unguja and lowest in Kibaha. It was also observed that $\mathrm{Ka}$ band satellite links suffer higher rain attenuation than $\mathrm{Ku}$ band satellite links. The higher values of rain attenuation observed are due the fact that the coastal area in Tanzania experience high rainfall intensity as compared to the one specified by ITU-R. Thus, applying point rain rate predicted using the collected surface data is of more significant in the accurate prediction of rain induced attenuation. The results obtained from this study can be used in a preliminary design of satellite link budget to enhance the signal propagation of earth-satellite microwave links in the coastal area of Tanzania. Future studies are proposed to obtain one-minute rain rate cumulative distribution for the remaining locations in the country and to develop rain rate and rain attenuation contour maps for Tanzania satellite links.

\section{REFERENCES}

[1] A. I. Sakir Hossain, “Estimation of Rain Attenuation at EHF bands for Earth-to-Satellite Links in Bangladesh,” Int. Conf. Electr. Comput. Commun. Eng., pp. 589-593, 2017.

[2] S. J. Malinga, P. a Owolawi, and T. J. O. Afullo, "Estimation of Rain Attenuation at C, Ka, Ku and V Bands for Satellite Links in South Africa," Proc. PIERS Taipei, March 25-28, 2013, pp. 948-958, 2013.

[3] T. S. Ibiyemi, M. O. Ajewole, J. S. Ojo, and O. O. Obiyemi, "Rain rate and rain attenuation prediction with experimental rain attenuation efforts in south-western Nigeria," 2012 20th Telecommun. Forum, TELFOR 2012 Proc., no. 1, pp. 327-329, 2012.

[4] T. V Omotosho, O. O. Obiyemi, J. S. Mandeep, M. Abdullah, and S. A. Akinwumi, "Review of rain attenuation measurements on earth -space links in nigeria 2015,” Proceeding 2015 Int. Conf. Sp. Sci. Commun., pp. 0-4, 2015.

[5] R. E. Okoola, "A diagnostic study of the eastern Africa monsoon circulation during the Northern Hemisphere spring season," Int. J. Climatol., vol. 19, no. 2, pp. 143-168, 1999.

[6] G. Ononiwu, S. Ozuomba, and C. Kalu, "Determination of the Dominant Fading and the Effective Fading for the Rain Zones in the Itu-R P.838-3 Recommendation,” Eur. J. Math. Comput. Sci., vol. 2, no. 2, 2015.

[7] H. Sakir, "Rain Attenuation Prediction for Terrestrial Microwave Link in Bangladesh," J. Electr. Electron. Eng., 2014.

[8] S. Selamat, A. Syafiah, M. Marzuki, A. T. Azlan, A. Naemat, and K. Khalil, "60-min to 1-min Rainfall Rate Conversion Using East Malaysia Data," no. 3, pp. 1-5, 2014.

[9] M. O. Fashuyi, P. A. Owolawi, and T. J. Afullo, "Rainfall Rate Modeling for LOS Radio Systems in South Africa," vol. 97, no. March, pp. 74-81, 2006.

[10] J. S. Ojo, M. O. Ajewole, and L. D. Emiliani, "One-minute rain-rate contour maps for microwave-communicationsystem planning in a tropical country: Nigeria,” IEEE Antennas Propag. Mag., vol. 51, no. 5, pp. 82-89, 2009.

[11] C. T. Mulangu, P. A. Owolawi, T. J. O. Afullo, and S. Member, "Rainfall Rate Distribution for LOS Radio Systems in Botswana," no. 3.

[12] F. D. Diba, T. J. Afullo, and A. A. Alonge, "Rainfall Rate and Attenuation Performance Analysis at Microwave and Millmeter Bands for the Design of Terrestrial Line-of-Sight Radio Links in Ethiopia," vol. 107, no. September, pp. 177-186, 2016.

[13] D. Sumbiri, T. J. O. Afullo, and A. Alonge, "Rain Attenuation Prediction for Terrestrial Links at Microwave and Millimeter Bands over Rwanda," pp. 8-11, 2016.

[14] S. Shrestha and D. Choi, "Proposed One-Minute Rain Rate Conversion Method for Microwave Applications in Korea," vol. 14, no. 3, pp. 153-162, 2016.

[15] A. F. Ismail, W. Hashim, K. Abdullah, and N. A. Malik, "Empirical conversion of rainfall rate distribution for various integration times in Malaysia," 2011 IEEE Int. RF Microw. Conf. RFM 2011-Proc., no. December, pp. 270-273, 2011.

[16] F. Abiola, R. Mohd-mokhtar, and T. Victor, "Analysis of Cumulative Distribution Function of 2-year Rainfall Measurements in Ogbomoso, Nigeria," no. February, pp. 171-179, 2012.

[17] P. Owolawi, "Derivation of One-minute Rain Rate from Five-minute Equivalent for the Calculation of Rain Attenuation in South Africa," PIERS Online, vol. 7, no. 6, pp. 524-535, 2011.

[18] F. Moupfouma and L. Martin, "Modelling of the rainfall rate cumulative distribution for the design of satellite and terrestrial communication systems," Int. J. Satell. Commun., vol. 13, no. 2, pp. 105-115, 1995.

[19] J. Chebil and T. A. Rahman, "Development of 1 Min Rain Rate Contour Maps for Microwave Application in Malaysia Peninsula,” Electron. Lett., vol. 35, no. 20, pp. 1772-1774, 1999.

[20] P. L. Rice and N. R. Holmberg, "Cumulative Time Statistics of Surface-Point Rainfall Rates," IEEE Trans. Commun., vol. 21, no. 10, pp. 1131-1136, 1973.

[21] P. Series, "Characteristics of precipitation for propagation modelling P Series Radiowave propagation," vol. 7, 2017. 
[22] G. R. Rimven, K. S. Paulson, and T. Bellerby, "Estimating One-Minute Rain Rate Distributions in the Tropics From TRMM Satellite Data (October 2017),” IEEE J. Sel. Top. Appl. Earth Obs. Remote Sens., vol. 11, no. 10, pp. 3660-3667, 2018.

[23] A. Y. Abdulrahman, T. B. A. Rahman, S. K. B. A. Rahim, and M. Rafi Ul Islam, "A New Rain Attenuation Conversion Technique for Tropical Regions," Prog. Electromagn. Res. B, vol. 26, no. September, pp. 53-67, 2010.

[24] R. Itu-r, "RECOMMENDATION ITU-R P.838-3 Specific attenuation model for rain for use in prediction methods," pp. 1-8, 2005.

[25] ITU-R, "Propagation data and prediction methods required for the design of Earth-space telecommunication systems," Recomm. ITU-R P.618-8, vol. 12, pp. 1-24, 2015.

\section{BIOGRAPHIES OF AUTHORS}
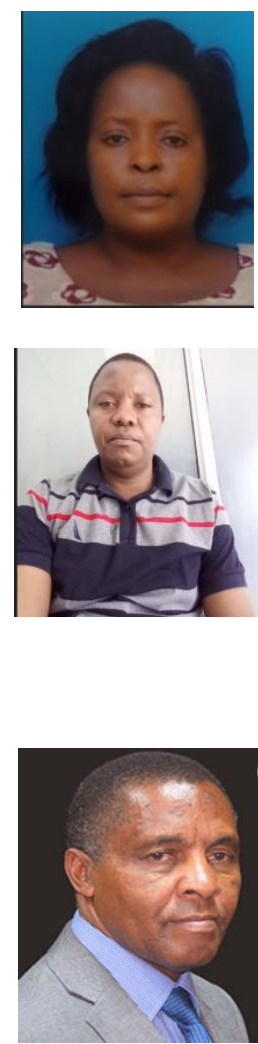

Promota Haule received BEng in Electronics and Telecommunication Engineering from Dar es salaam Institute of Technology (DIT), Dar es Salaam, Tanzania in 2009 and MSc in Electronic systems with Communications from University of Warwick, Coventry, United Kingdom in 2012. In 2013 was an assistant lecturer of Electronics and Telecommunication Engineering at Dar es Salaam Institute of Technology. Currently she is a member of Wireless Communication Research Group in University of Dar es Salaam and she is working towards a $\mathrm{PhD}$ degree in Telecommunication Engineering at University of Dar es Salaam. Her research interests are in Telecommunications Engineering and RF propagation.

Hashim Uledi Iddi graduated B.Sc. degree in Electrical Engineering from the University of Dar es Salaam, Dar es Salaam, Tanzania in 2001 and M.Sc. degree in Telecommunications Engineering from the University of Dar es Salaam in 2005. Since 2005 he joined at University of Dar es salaam as Assistant lecturer. He then obtained his PhD in Electrical Engineering in 2014 from Universiti Teknologi Malaysia (UTM), Malaysia in antenna design for MIMO application. He is now Lecturer in the Department of Electronics and Telecommunications Engineering, College of Information and Communications Technology, University of Dar es Salaam. His research interests include Wireless propagation, antenna design for Wireless communications and Powerline communications (PLC). He is a registered Engineer and IEEE member. Currently, supervising four (4) PhD students and a number of Masters students.

Eng. Dr. M.M. Kissaka received B.Sc. degree in Electrical Engineering from the University of Dar es Salaam (UDSM), Dar es Salaam, Tanzania in 1989 and Ph.D. degree in Telecommunications Engineering from the University of Manchester, United Kingdom in 1994. He served as Head of department for more than eight years and as Director, Centre for Virtual Learning (CVL) for three (3) years at UDSM. Currently Dr Kissaka is the Principal, College of Information and Communication Technologies (CoICT) and member of Senate at the University of Dar es Salaam. Eng. Dr. M.M. Kissaka is a registered Professional Engineer with the Engineers Registration Board (ERB) in Tanzania since 2003 in the telecommunications engineering field. He has performed numerous consultancy assignments related to electronics, telecommunications and ICT. Currently he is a Senior Lecturer in the Department of Electronics and Telecommunications Engineering, College of Information and Communication Technologies (CoICT), University of Dar es Salaam. His research interest includes Wireless Communication and e-Learning. 